Bull. Fac. Agric., Cairo Univ. , 69:255-264 (2018).

\title{
DESIGNING AN INDEX FOR CRITERIA OF THE SERVICE QUALITY ASSURANCE IN AGRICULTURAL EXTENSION IN EGYPT (SERVQUALEX)
}

(Received:29.11.2018)

By

A.M. Diab

Department of Rural Sociology and Agricultural Extension, Faculty of Agriculture, The New Valley University, Egypt

\begin{abstract}
The purpose of the present study is to design and validate an index for the criteria of service quality assurance of the agricultural extension organization of Egypt (SERVQUALEX), to be used in the case of implementing quality assurance standards in agricultural extension. By reviewing the available relevant literature concerning service quality assurance, four key dimensions could be considered as essential components of the proposed scale ,namely:1) Tangibles and core of service; 2) Human element of extension service delivery; 3 ) Systematization of extension service delivery (nonhuman element); and 4) Social responsibility of extension system. In order to achieve the study objective, 50 opinion leaders from the New Valley Governorate were selected to be the sample of the study. Data were collected during March 2018 through personal interviews using a questionnaire form. Percentages, average, standard deviation, Pearson's correlation coefficient, and reliability and validity analysis tests were used for data presentation and analysis. Reliability coefficient (Cronbach's Alpha) was about 0.964 , and internal validity coefficient was 0.982 . By testing the internal validation using Pearson's correlation coefficient, the final version of the scale contained 43 statements of which: 9 for Tangibles and core of service component; 13 for Human element of extension service delivery; 10 for Systematization of extension service delivery (non-human element), and 11 for Social responsibility of extension system.
\end{abstract}

Key words: Quality assurance, service quality, agricultural extension, Egypt.

بناء مقياس لمعايير ضمان جودة الخدمة المقدمة من الإرشاد الزراعي في مصر (SERVQUALEX)

$$
\begin{aligned}
& \text { أحمد محمد دياب } \\
& \text { قسم المجتمع الريفي و الإرشاد الزر اعي، كلية الزراعة، جامعة الوادي الجديد، الوادي الجديد، مصر }
\end{aligned}
$$

ملخص جمان

يستهدف البحث محاولة تصميم مقياس لمعايير ضمان جودة الخدمة في الإرشاد الزراعي (SERVQUALEX)

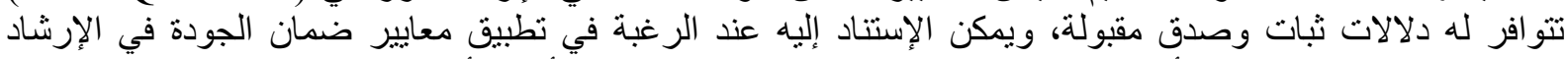

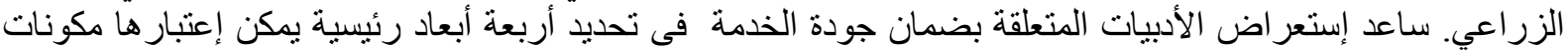

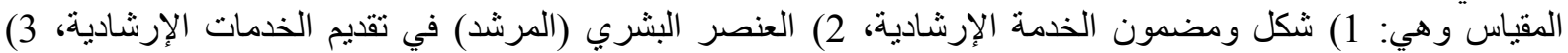

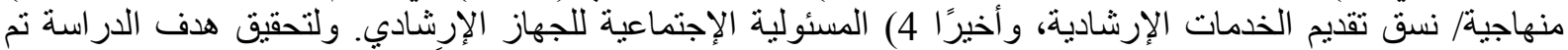

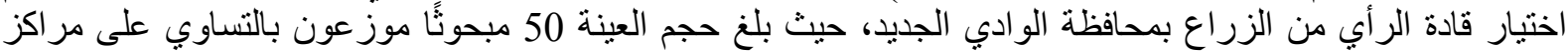

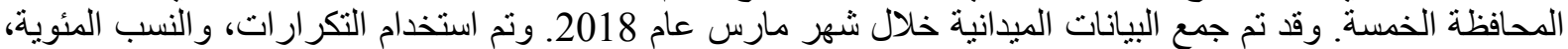

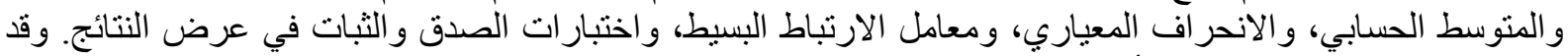

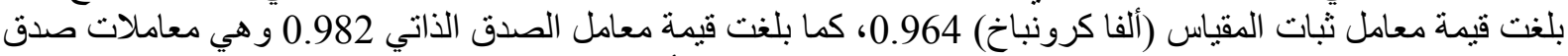

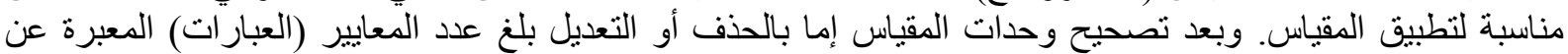
المقياس 43 عبارة منها 9 معايير تمثل شكل ومضمون الخدمة الإرشادية ، 13 لمحور العنصر البشري (المرشد) في تقديم 
الخدمات الإرشادية، 10 لمحور التنظيم في تقديم ومتابعة الخدمات الإرشادية (العنصر غير البشري)، وأخيرًا 11 لدحور المسئولية الإجتماعية للجهاز الإرشادية

العامة فهي لا تقتصر على عملية إثباع الحاجات الظاهرة

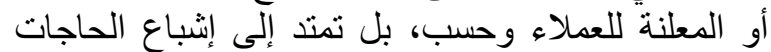

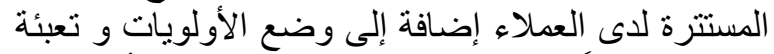

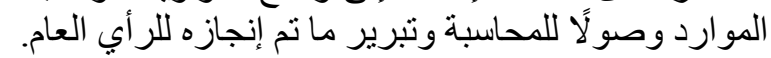

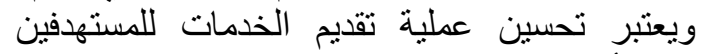

واحدة من أكبر التحديات التي تواجه القطاع العام حول

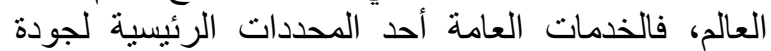

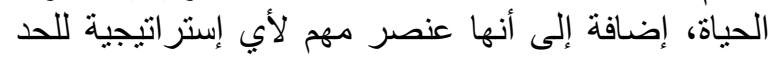

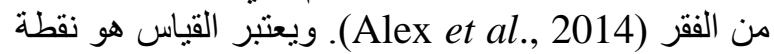

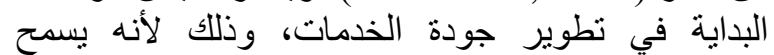
بالمقارنة بين التغيرات السابقة و اللاحقة لتحديد المشكلات

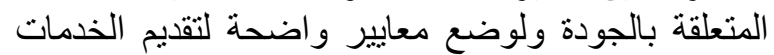

.(Daniel \& Berinyuy, 2010)

يوجد عدد من المقاييس، تم تطويرها والتحقق من

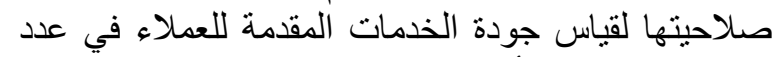
من المنظمات ومن أهم هذه المقاييس ما يلي:

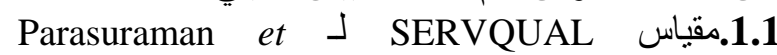
(1988)

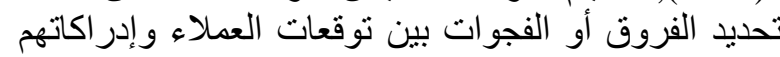
للخدمة. ويتكون المقياس من 5 عناصر رئيسية تصنية تضم 22 عنصر فرعي ينم خلالها تقييم كل من توقعات المنات المستهدقين

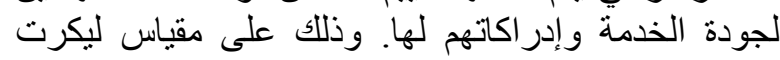

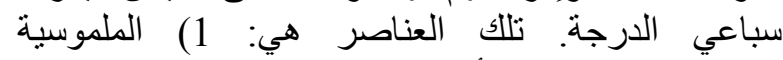
4angibles

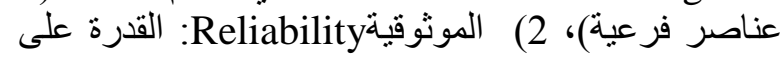

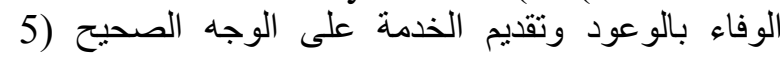

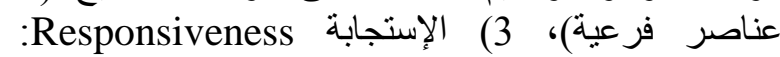
التعامل بسرعة من مقدمي الخدمة لحل المشكلات غير الحزية

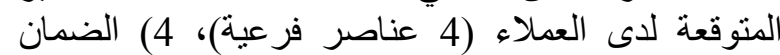
: Assurance

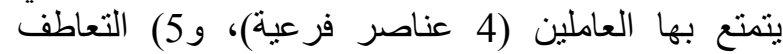
Empathy وفهم العملاء وتعني الإهنمام الذي يمكن ألن تودئ توليه المنظمة للعملاء بشكل فردي (5 عناصر فرعية). وبتطبيق المعادلة التئلة ،(service quality= Perceptions - Expecttations) فلو كانت النتيجة سالبة دل ذللك على عدم رضا المستهدفين

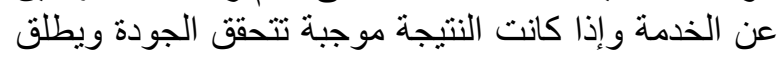

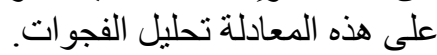

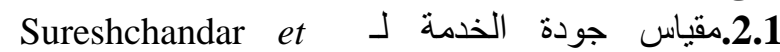

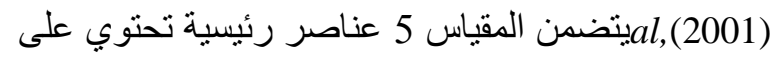

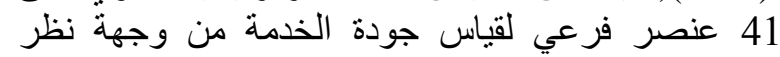

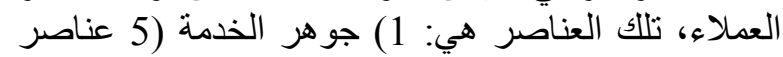
فرعية) 2) العنصر البشري في التقديم الخدمة (17 الخدمة (5 عنصر

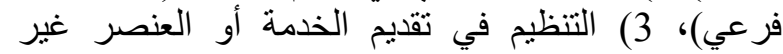

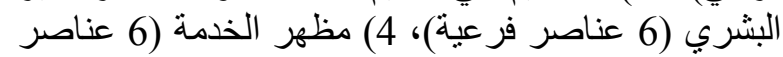

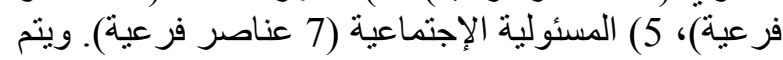

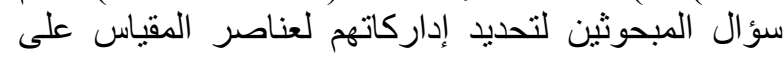

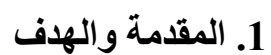

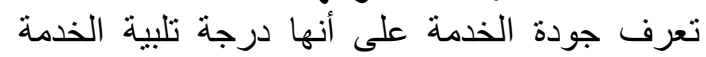

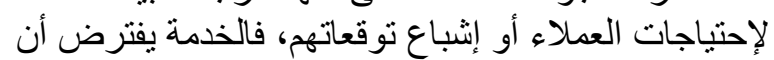

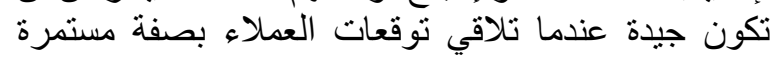
.(El Saghier \&Nathan, 2013) وتعتبر جودة الخدمة أحد الأبعاد الضرورية

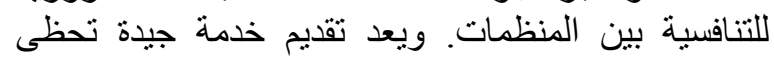

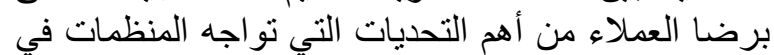

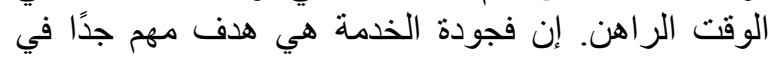

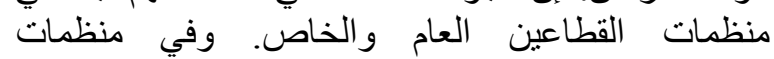
الأعمال Business و الخدمات Subices (Shahin \& Samea, 2010). وينظر إلى جودة الخدمة

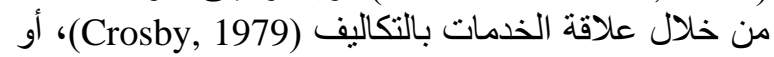

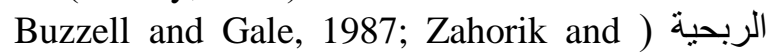
‘Rust, 1992; Rust and Zahorik, 1993 أورضا العملاء (Boltan and Drew, 1991; (Boulding et al., 1993 (Reichheld and Sasser, 1990)، أُ النوايا السلوكية والسمعة الطيبة للمنظمة (2004) 2004)، أو كل ما سبق في آن والنة واحد.

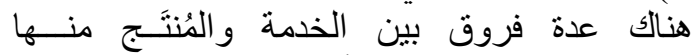

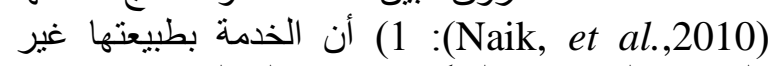

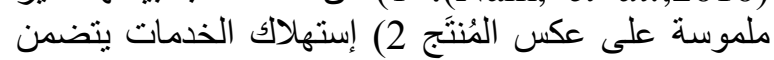

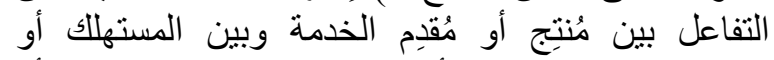

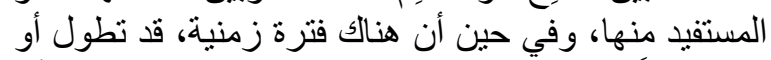

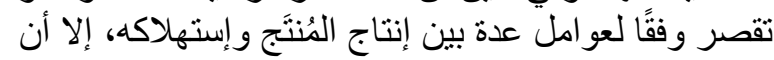

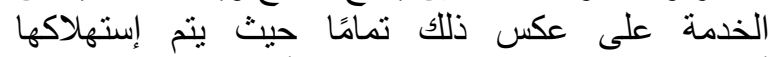

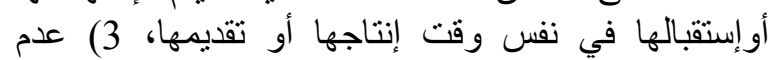
إمكانية الإحتفاظ بالخدمة لإستخدامها عند الحاجة على تلى على

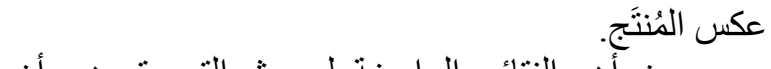
ومن أهم النتائج الراسخة لبحوث التسويق هي أن الن النقي

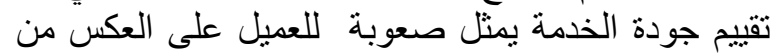

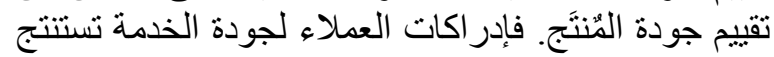

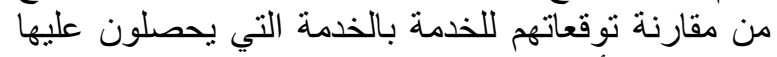

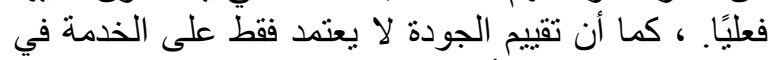

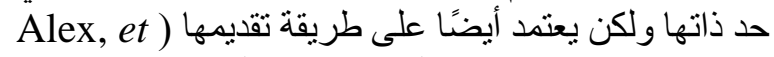

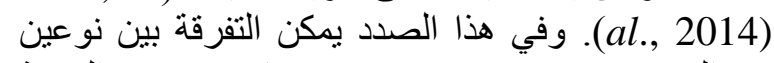

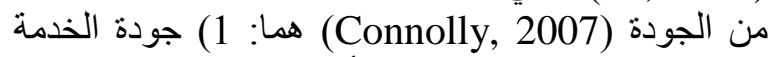

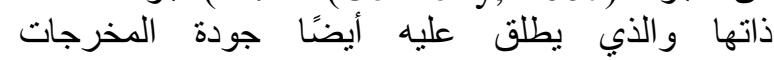
technical او الجودة الفيطنًات الفنية outcomes quality وأو الجودة المادية الفيزيقية quality

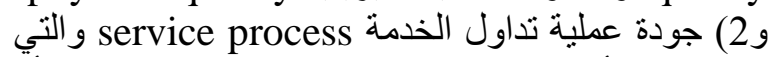

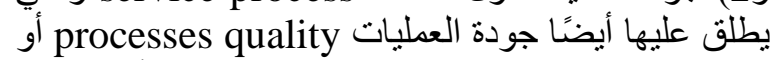
الجودة الوظيفية functional quality أو جودة جلودة التفاعلات (المتبادلة) interaction quality

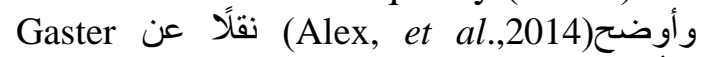
(1995)أنه نظرًا لتعقد عملية تقديم الخدمات في المنظمات 
الارشادية:منهاجية أو نست تقديم ومتابعة الخدمات

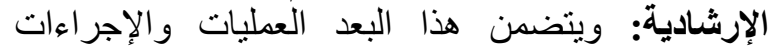

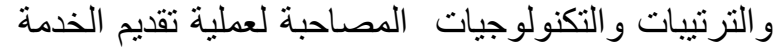
وهي نتشير إلى العنصر غير البشات الثري في عملية تقديم الخدمات للعملاء، فالعميل أو مستقبل الخدمة ينوقيل فئر أن تتسم

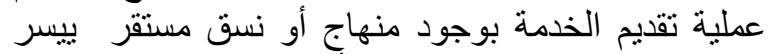
إستقبالهم للخدمات دون عناء أو دون إستجداء مقدمي مقدي

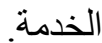

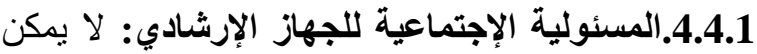

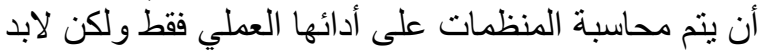

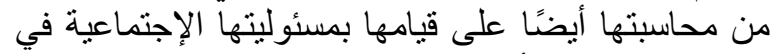

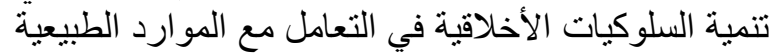

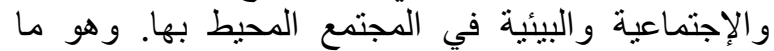

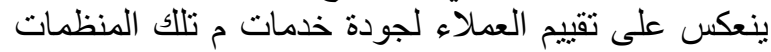

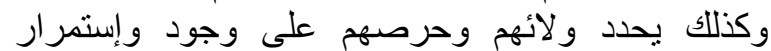

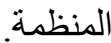

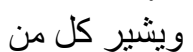

Abdel-Ghany and Abdel-Salam Ruhana (2010) بمكان للمنظمات الخدمية مثل الإرشاد الزر اعي إذا كان الخدان لها

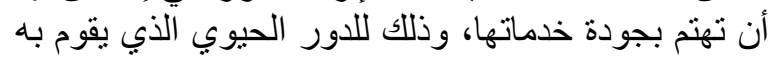

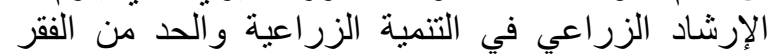

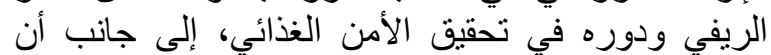

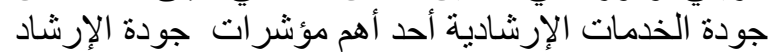

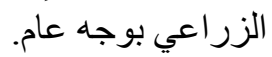

فيجب على الإرشاد الزراعي أن يهتم بجودة الخدمات

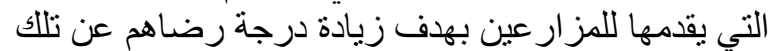

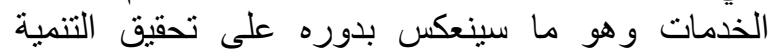
الزراعية (Abdel-Ghany and Diab, 2015)

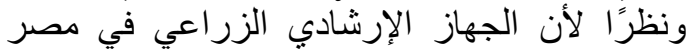
بحاجة إلى الإصلاح وإعادة الهيكلة في جميع جوانئ النيه

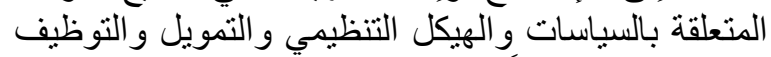

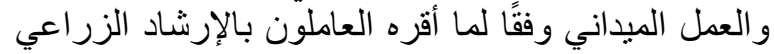

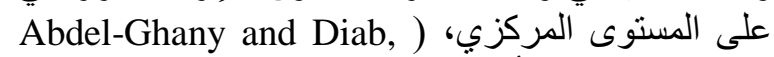
2013). لذا تتضح أهمية تطبيق معايير ضمانية الإني الجودة في

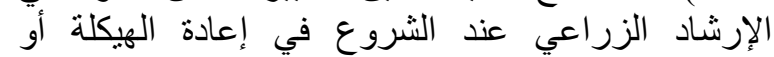

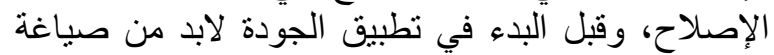

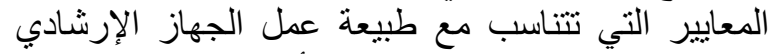

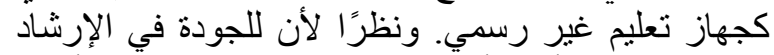

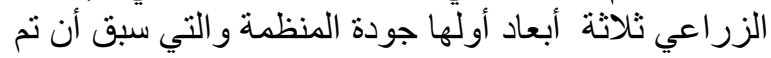

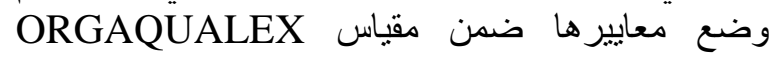
(دياب، 2017) وثانيها جودة الإدارة و التي قد سبق وضع

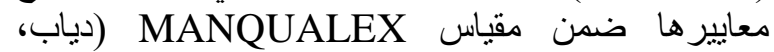
2018) وثالثها جودة الخدمات التئي بقدمها الإرشاد

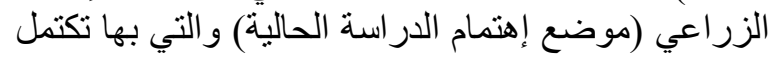

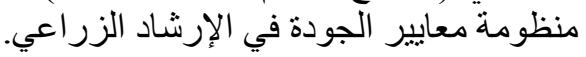

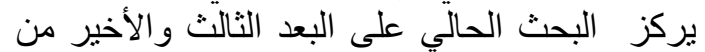

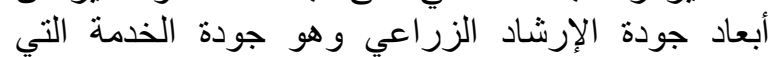

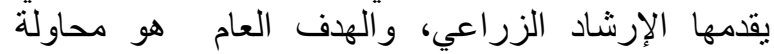

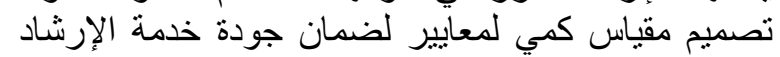

تدريج خماسي من غير موافق مطلقًا (درجة واحدة) إلى

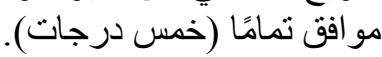

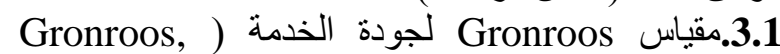

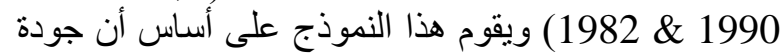

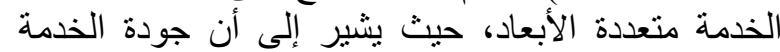

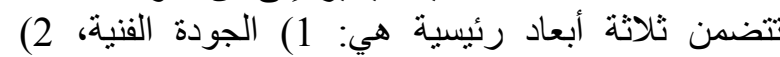

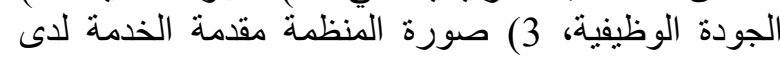
العملاء. ويتضمن محور الجودة الفنبة الخصائص المدرة المدركة

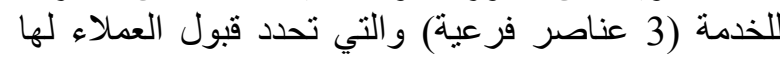

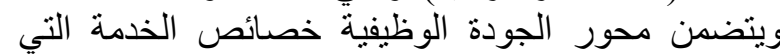

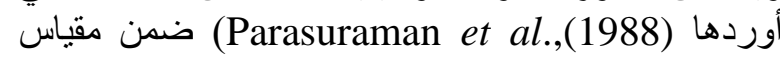
SERVQUAL

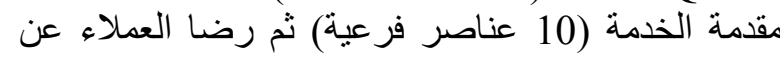

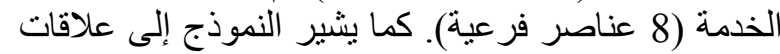

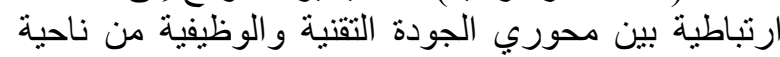

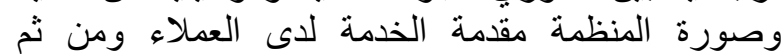

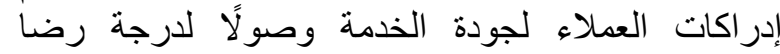
العملاء عن هذه الخدمة.

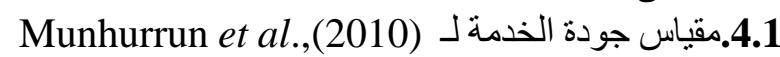
ويمثل الصورة المعدلة من مقياس SERVQUAL ليناسب لئس

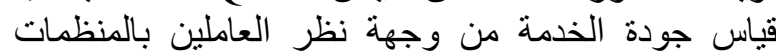

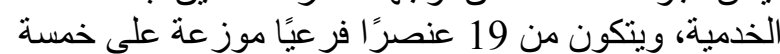

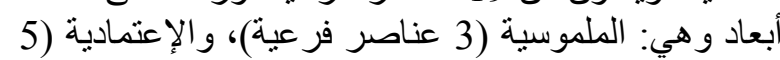

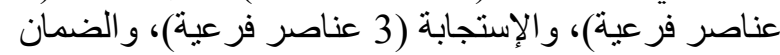

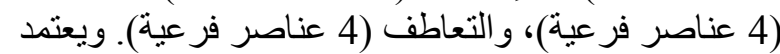
المقياس على تحديد جودة الخدمة بالإعتماد على قلى قياس الفجوة بين إدراكات العاملين للواقع الفعلي لأبعاد جودة الألئ الخدمة وتوقعاتهم حول تللك الأبعاد. وبإستطلاع الأدبيات و والمقاييس الماد المتعلقة بجودة الخدمة، ( Gronroos, 1982 and 1990; Parasuraman Sureshchandar et al., 2001; et al., 1988; (Munhurrun et al., 2010 لجودة الخدمة على النحو التالي: الني:

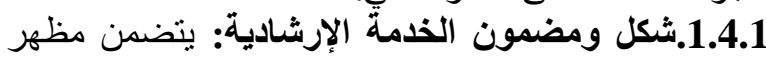

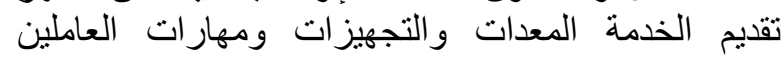

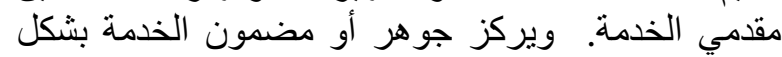

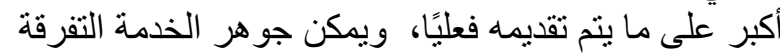

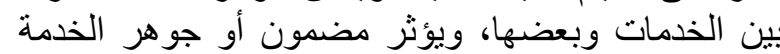
على تقييم العملاء لجودة الخدمة الخدمة المقدمة.

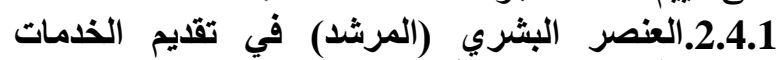
الإرشادية: ويتضمن الأبعاد الخمسة التي تناولها مقيم التياس SERVQUAL (توافر وجاذبية ومناسبة التسهيلات المادية والتجهيزات

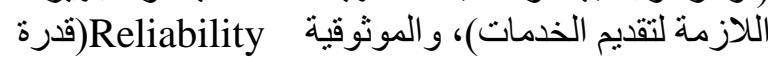

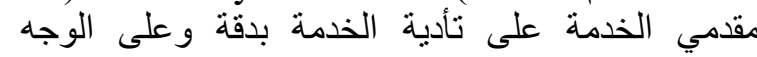

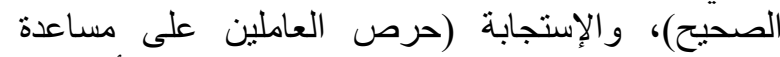

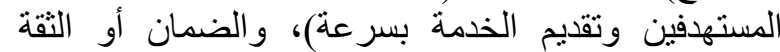

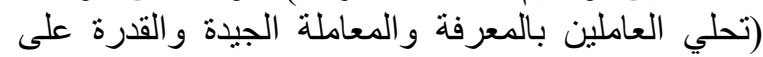

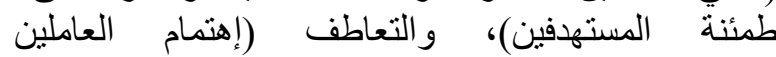

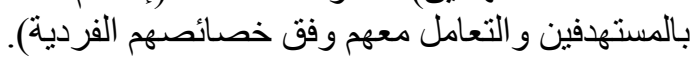


بإضـافة وحدات أخرى تحقق انسجام الاسـتمارة، وعقب

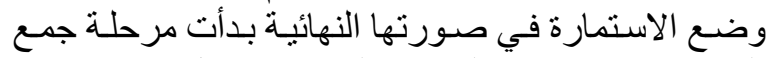
البيانات، وقد تم جمع البيانـات الميدانيـة خـلال شهر مـارس .2018 4.2.أدوات التحليل الإحصائي

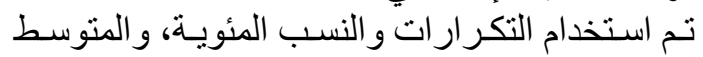

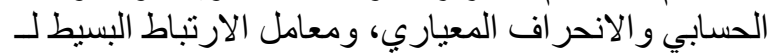

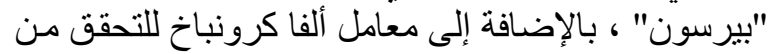
ثبات وصدق وصلاحية المقياس.

\section{3. إعداد المعايير}

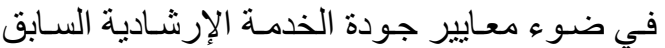

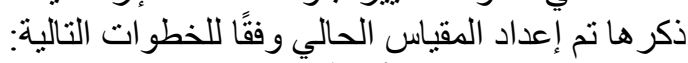

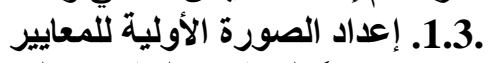

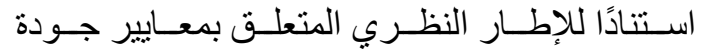

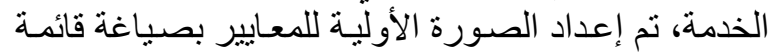

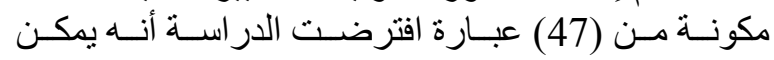

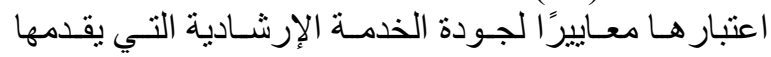

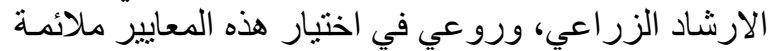
محتو اها لقياس أبعاد جودة الخدمة التئ. 1.1.3. الصدق الظاهري للمقياس الطئ

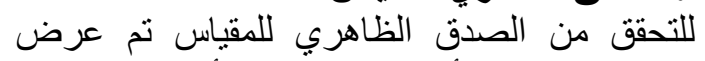

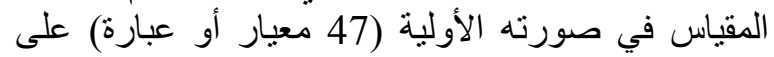

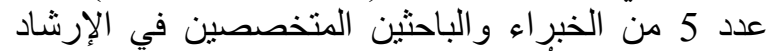
الزراعي، وقد طُلب من المحكمين إبداء آرائهم في درجي الإرجة

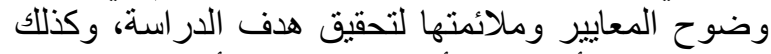

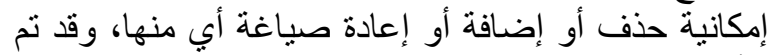

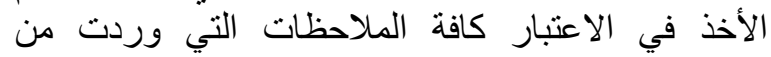

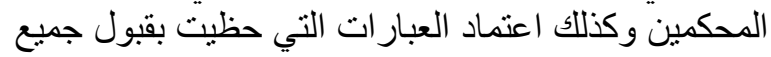

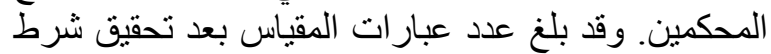

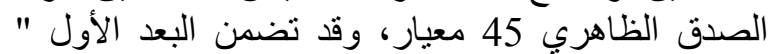

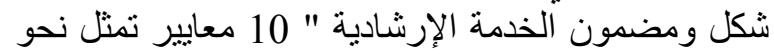

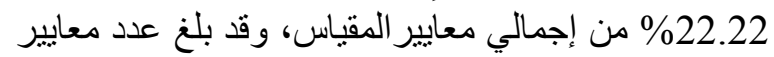

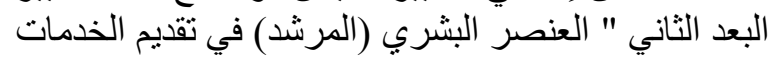

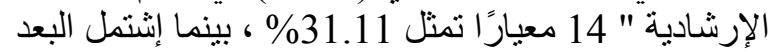

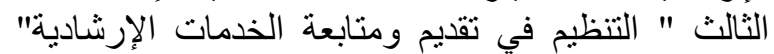

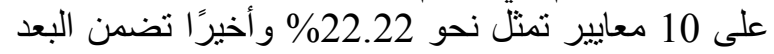

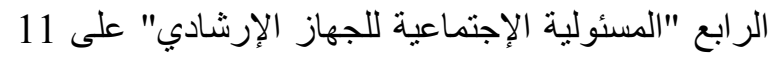

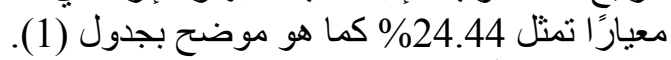

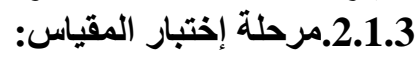

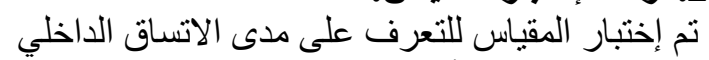

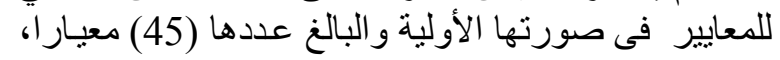

الزراعي في مصر، SERVICE QUALITY In EXTENSION SERVICE والمشتقة من عبارة QUALITY In EXTENSION وصدق مقبولة، و يسهل نطبيقه عند الرغبة في نطبيق

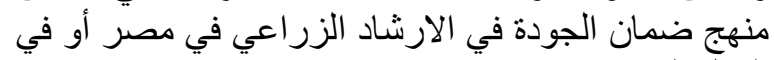

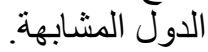

\section{2 ـالطريقة البحثية}

12. منهج الدراسة. اعتمدت الدر اسة علي منهج المسح الاجتماعي بالعينة

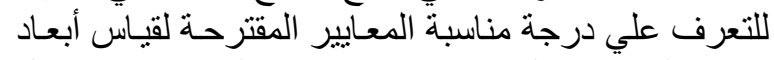

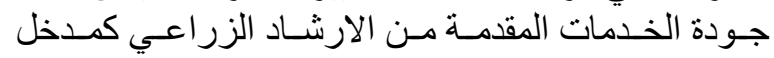

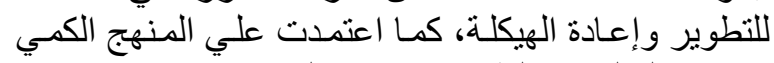

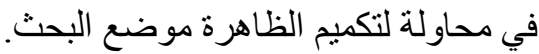
2.2.2 المفاهيم الإجرائية

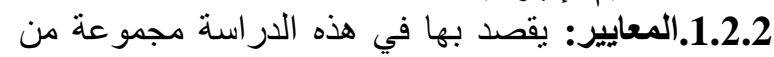

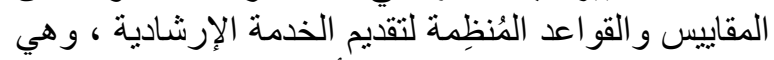

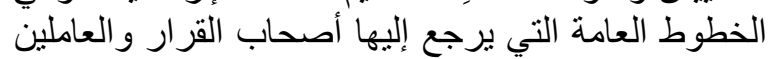

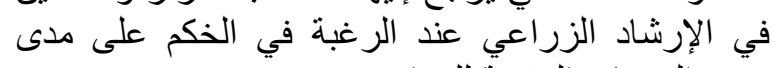

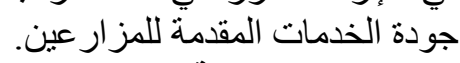

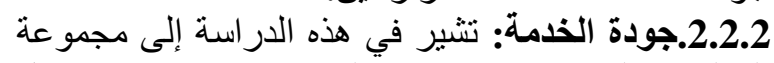

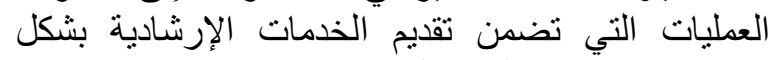

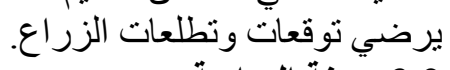

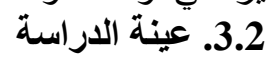

نظرًا لأن الهدف من الدراسة الإسة هو بناء مقياس لمعايير

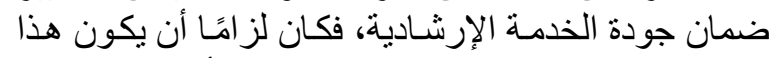

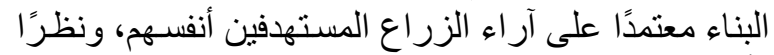

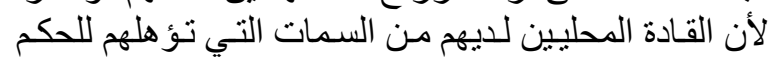

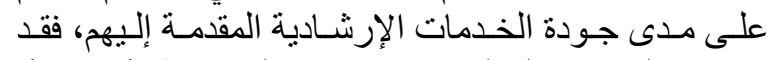

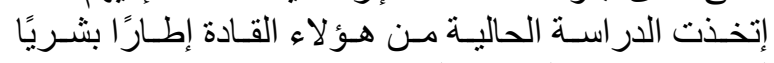

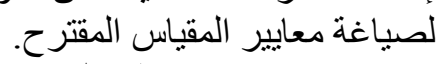

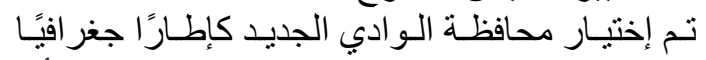

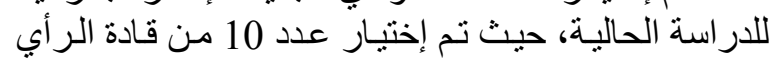

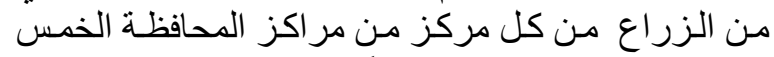

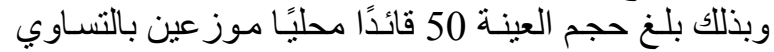
على مر اكز المحافظة ولتحقيق هدف الدر اسة تم تصميم استمارة استبيان تم تمعن

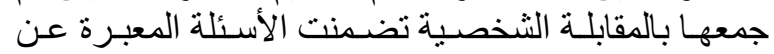

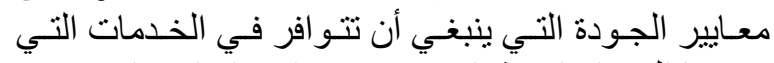

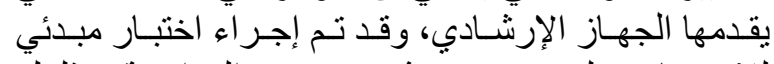

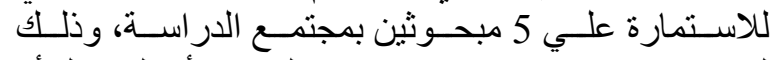

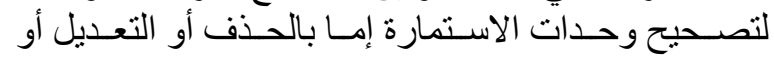

جدول (1) عدد ونسبة المعايير في كل بعد من أبعاد جودة الخدمة الإرشادية بصيغتها الأولية وبعد تحقيق الصدق الظاهري لها.

\begin{tabular}{|c|c|c|c|c|}
\hline \multicolumn{2}{|c|}{ بعد تحقيق الصدق الظاهرى } & \multicolumn{2}{|c|}{ الصورة الأولية } & \multirow{2}{*}{ أبعاد المقياس } \\
\hline$\%$ & عدد المعايير & $\%$ & عدد المعاييز & \\
\hline 22.22 & 10 & 21.28 & 10 & البعد الأول: شكل ومضمون الخدمة الإرشادية \\
\hline 31.11 & 14 & 31.91 & 15 & البعد الثاني: العنصر البشري (المرشد) في تقديم الخدمات الإرشادية \\
\hline 22.22 & 10 & 23.40 & 11 & البعد الثالت: التنظيم في تقديم ومتابعة الخدمات الإرشادية \\
\hline 24.44 & 11 & 23.40 & 11 & البعد الرابع: المسئولية الإجتماعية للجهاز الإرشادي \\
\hline 100 & 45 & 100 & 47 & المقياس الكلي \\
\hline
\end{tabular}

المصدر : بيانات الدراسة 


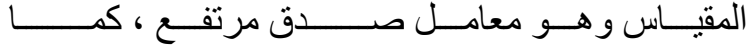

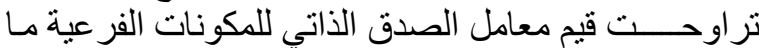

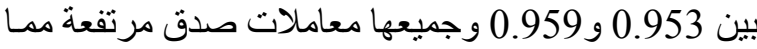

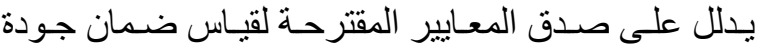
الخدمة المقدمة من الجهاز الإرشادي.

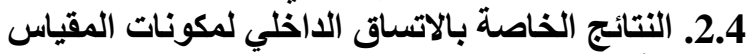

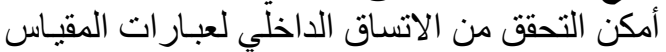

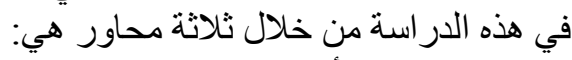

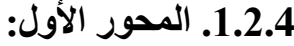

الإتسـاق الـداخلي Guterual Consistency أي الإول:

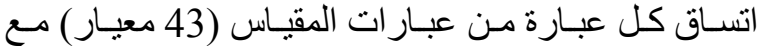

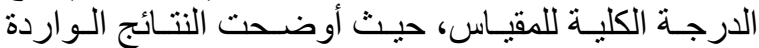

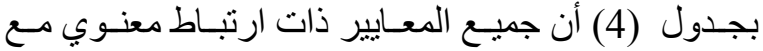
المجموع الكلي للمقياس علي مستوى

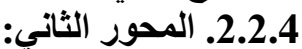

اتساق كل عبارة مع درجة العنصر التهائ (المكون الفرعي)

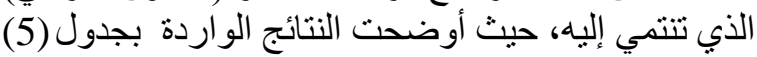

وذلك علكى عينـة مسن المبحـوثين ، وتـم ترميـز اسـتجابات

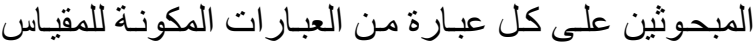

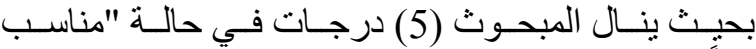

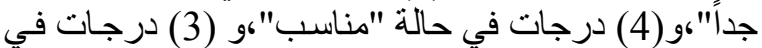

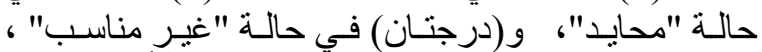

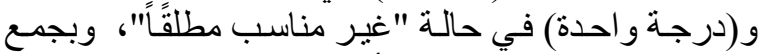

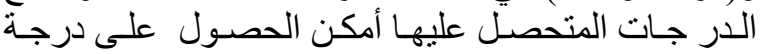

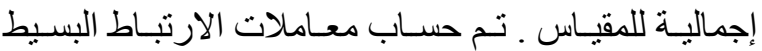

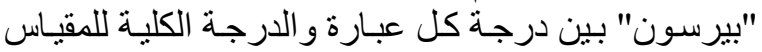

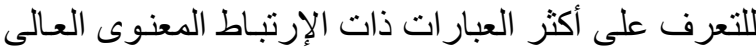

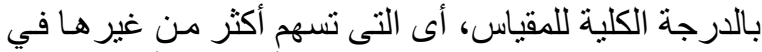
قياس درجة جودة الخدمة الإرشادية بأبعادها الأربعة سـالفة فيرة الذكر.

و أشتارت قيم معاملات الارتباط، باستبعاد عبـارتين

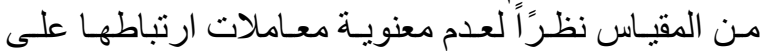

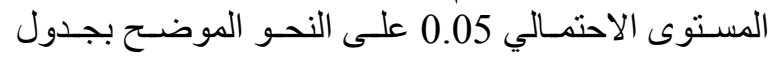

جدول (2) معاملات ارتباط الوحدات الأولية لمعايير جودة الخدمة التي يقدمها الإرشاد الزراعي مع الارجة الكلية للمقياس.

\begin{tabular}{|c|c|c|c|c|c|c|c|c|}
\hline الارتباط معامل & المعيار & الارتباط معامل & رقام & الارتباط & المعيار & الارتباط معامل & المعيار & أبعاد المقياس \\
\hline 0.637 & 4 & * 0.678 & 3 & *0.954 & 2 & 0.048 & 1 & \multirow{3}{*}{ الخدمة الإرشادية: شكل ومضمون } \\
\hline 0.730 & 8 & *0.737 & 7 & 0.445 & 6 & *0.753 & 5 & \\
\hline$\times \times$ & $\times \times$ & $x \times$ & $\times \times$ & 0.906 & 10 & 0.637 & 9 & \\
\hline 0.692 & 14 & 0.780 & 13 & 0.741 & 12 & 0.869 & 11 & \multirow{4}{*}{ 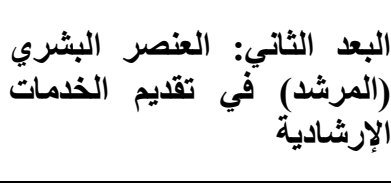 } \\
\hline 0.912 & 18 & 0.522 & 17 & 0.528 & 16 & 0.555 & 15 & \\
\hline 0.703 & 22 & 0.670 & 21 & 0.815 & 20 & 0.734 & 19 & \\
\hline$\times x$ & $x \times$ & $x \times$ & $x \times$ & 0.048- & 24 & 0.749 & 23 & \\
\hline${ }^{* * *} 0.605$ & 28 & 815. & 27 & 0.749 & 26 & 0.742 & 25 & \multirow{3}{*}{ ومتابعة الخدمات الإرشيادية في تقديم } \\
\hline${ }^{* * *} 0.865$ & 32 & 562. & 31 & *0.879 & 30 & *0.658 & 29 & \\
\hline$\times \times$ & $\times \times$ & $\times \times$ & $\times \times$ & 0.574 & 34 & 0.897 & 33 & \\
\hline 0.895 & 38 & 0.574 & 37 & 0.919 & 36 & 0.703 & 35 & \multirow{3}{*}{ الإجتماعية للابعهاز الإرشادي } \\
\hline 0.520 & 42 & 0.524 & 41 & 0.678 & 40 & 0.954 & 39 & \\
\hline$\times x$ & $x \times$ & 0.678 & 45 & 0.678 & 44 & *0.912 & 43 & \\
\hline
\end{tabular}

0.01 * معنوي علي مستوي

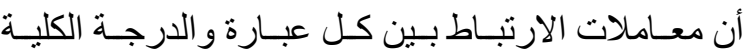

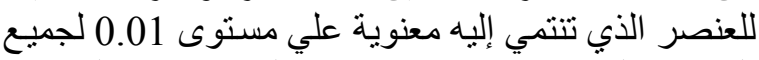

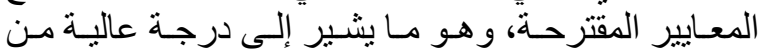

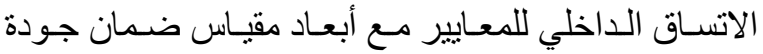

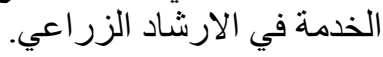

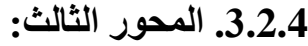

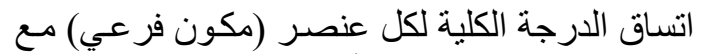

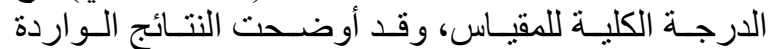

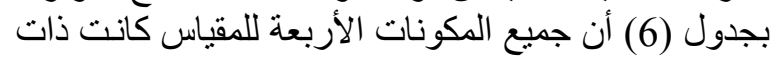

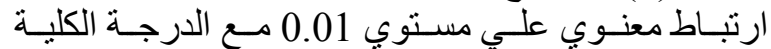

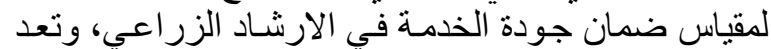

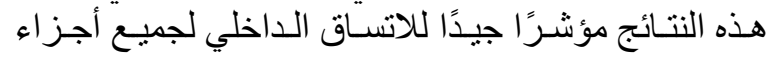

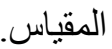

المصدر : عينة الدر اسة معنوي علي مستوي 0.05

\section{4. نتائج الاراسة}

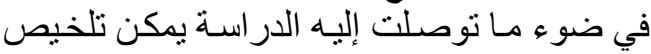

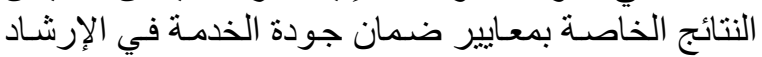
الزر اعي من خلاج البنود التالية:

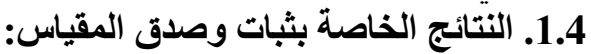

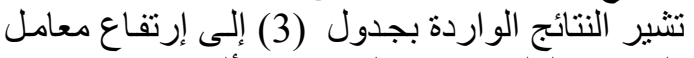

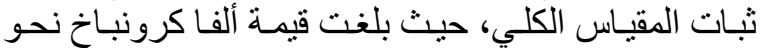

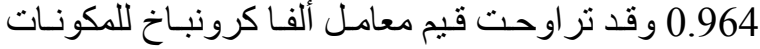
الفرعية للمقياس (4 مكونات فرعية) بين وجميعها قيم تدل علي ثبات المقياس.

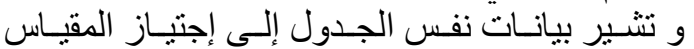

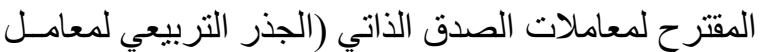

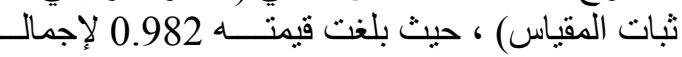


جدول (3) نتائج التحليل الإحصائي للوحدات (المعايير)التي استوفت شروط تكوين مقياس معايير جودة الخدمة في الجهاز الارشادي.

\begin{tabular}{|c|c|c|c|c|c|}
\hline الصدقة & 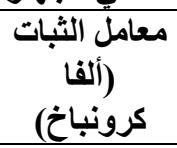 & الالاحياري & الحستوسي & $\begin{array}{c}\text { (الوحدات } \\
\text { (المعايير) }\end{array}$ & المكونات الفرعية للمقياس \\
\hline 0.959 & 0.920 & 5.49 & 39.22 & 9 & 1. شكل ومضمون الخدمة الإرشادية \\
\hline 0.954 & 0.910 & 6.69 & 57.44 & 13 & 2. العنصر البشري (المرشد) في تقديم الخدمات الإرشادية \\
\hline 0.957 & 0.916 & 5.21 & 44.98 & 10 & 3. التنظيم في تقديم ومتابعة الخدمات الإرشادية \\
\hline 0.953 & 0.909 & 5.49 & 49.22 & 11 & 4. المسئولية الإجتماعية للجهاز الإرشادي \\
\hline 0.982 & 0.964 & 21.83 & 190.86 & 43 & المقياس الكلي \\
\hline
\end{tabular}
المصدر : عبنة الدر اسة

جدول رقم (4) معاملات ارتباطوحدات المقياس مع الدرجة الكلية لمعايير جودة الخدمة المقدمة من الجهاز الارشادي ومتوسطاتها

\begin{tabular}{|c|c|c|c|c|c|c|c|c|c|c|c|}
\hline \multicolumn{12}{|c|}{ بية وانحر افتها المعيار } \\
\hline المعياري & الحستابي & الارتباط & r & الالانحراف & الحستوبي & معامل & P & الالحعراف & الحسابيى & معامل & $p$ \\
\hline 0.67 & 4.38 & $* * 0.623$ & 3 & 0.50 & 4.48 & $* * 0.684$ & 2 & 0.86 & 4.42 & $* * 0.955$ & 1 \\
\hline 1.18 & 4.14 & $* * 0.727$ & 6 & 0.68 & 4.30 & $* * 0.426$ & 5 & 0.79 & 4.32 & $* * 0.742$ & 4 \\
\hline 0.85 & 4.34 & $* * 0.911$ & 9 & 0.54 & 4.48 & $* * 0.642$ & 8 & 0.75 & 4.36 & $* * 0.718$ & 7 \\
\hline 0.67 & 4.40 & $* * 0.784$ & 12 & 0.51 & 4.50 & $* * 0.745$ & 11 & 0.83 & 4.26 & $* * 0.874$ & 10 \\
\hline 0.80 & 4.26 & $* * 0.526$ & 15 & 1.28 & 3.96 & $* * 0.553$ & 14 & 0.74 & 4.30 & $* * 0.692$ & 13 \\
\hline 0.88 & 4.44 & $* * 0.742$ & 18 & 0.48 & 4.66 & $* * 0.915$ & 17 & 0.78 & 4.36 & $* * 0.528$ & 16 \\
\hline 0.57 & 4.58 & $* * 0.706$ & 21 & 0.46 & 4.70 & $* * 0.670$ & 20 & 0.74 & 4.52 & $* * 0.822$ & 19 \\
\hline 0.50 & 4.52 & $* * 0.751$ & 24 & 0.50 & 4.52 & $* * 0.744$ & 23 & 0.51 & 4.50 & $* * 0.752$ & 22 \\
\hline 0.61 & 4.54 & $* * 0.664$ & 27 & 0.51 & 4.68 & $* * 0.607$ & 26 & 0.74 & 4.52 & $* * 0.822$ & 25 \\
\hline 0.79 & 4.46 & $* * 0.863$ & 30 & 0.95 & 4.40 & $* * 0.567$ & 29 & 0.71 & 4.52 & $* * 0.882$ & 28 \\
\hline 0.57 & 4.58 & $* * 0.706$ & 33 & 0.54 & 4.44 & $* * 0.583$ & 32 & 0.88 & 4.38 & $* * 0.900$ & 31 \\
\hline 0.76 & 4.50 & $* * 0.889$ & 36 & 0.93 & 4.42 & $* * 0.578$ & 35 & 0.68 & 4.54 & $* * 0.920$ & 34 \\
\hline 0.81 & 4.28 & $* * 0.521$ & 39 & 0.50 & 4.48 & $* * 0.684$ & 38 & 0.86 & 4.42 & $* * 0.955$ & 37 \\
\hline 0.50 & 4.48 & $* * 0.684$ & 42 & 0.48 & 4.66 & $* * 0.915$ & 41 & 0.78 & 4.38 & $* * 0.525$ & 40 \\
\hline$x x$ & $x \times$ & $x x$ & $x \times$ & $x \times$ & $x x$ & $x \times$ & $x x$ & 0.50 & 4.48 & $* * 0.684$ & 43 \\
\hline
\end{tabular}

جدول (5) معاملات ارتباط وحدات المكونات الفرعية النهائية لمعايير جودة الخدمة المقدمة من الارشاد الزراعي مع الدرجة الكلية

\begin{tabular}{|c|c|c|c|c|c|c|c|c|}
\hline \multicolumn{9}{|c|}{ لهذه المكونات الفرعية. } \\
\hline الارتباط & المعيار & الارتباط & المعيار & الارتباط & المعيار & الارتباط & المعيار & أبعاد المقياس \\
\hline 0.892 & 4 & 0.780 & 3 & 0.602 & 2 & 0.902 & 1 & \multirow{3}{*}{ الخدمة الإرشادية شكل ومضمون } \\
\hline 0.573 & 8 & 0.903 & 7 & 0.866 & 6 & 0.673 & 5 & \\
\hline$x x$ & $x x$ & $x x$ & $x x$ & $x x$ & $x x$ & 0.847 & 9 & \\
\hline 0.786 & 13 & 0.825 & 12 & 0.809 & 11 & 0.889 & 10 & \multirow{4}{*}{ الإلمرشدادية الثاني: العنصر البشري } \\
\hline 0.857 & 17 & 0.523 & 16 & 0.521 & 15 & 0.678 & 14 & \\
\hline 0.670 & 21 & 0.676 & 20 & 0.795 & 19 & 0.729 & 18 & \\
\hline$x x$ & $x x$ & $x x$ & $x x$ & $x x$ & $x x$ & 0.761 & 22 & \\
\hline 0.739 & 26 & 0.845 & 25 & 0.718 & 24 & 0.703 & 23 & \multirow{3}{*}{ 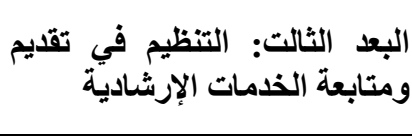 } \\
\hline * 0.843 & 30 & 0.709 & 29 & 0.879 & 28 & 0.770 & 27 & \\
\hline & & & & 0.598 & 32 & 0.841 & 31 & \\
\hline * 0.909 & 36 & $x^{*} 0.587$ & 35 & 0.858 & 34 & 0.729 & 33 & \multirow{3}{*}{ الإجتماعية الجرابعز الإرشادي } \\
\hline * 0.610 & 40 & * 0.556 & 39 & 0.712 & 38 & * 0.945 & 37 & \\
\hline$x x$ & $x x$ & 0.712 & 43 & 0.712 & 42 & 0.915 & 41 & \\
\hline
\end{tabular}


جدول (6) معاملات الارتباط البينية والمتوسطات الحسابية والانحرافات المعيارية للمكونات الفرعية الأربعة لمقياس جودة الخدمة المقدمة من الارشاد الزراعي.

\begin{tabular}{|c|c|c|c|c|c|}
\hline المقياس & (4) & (3) & (2) & (1) & أبعاد المقياس \\
\hline & & & & 1 & 1. شكل ومضمون الخدمة الإرشادية \\
\hline & & & 1 & 0.794 & 2. العنصر البشري (المرشد) في تقديم الخذمات الإرشادية \\
\hline & & 1 & * 0.949 & 0.805 & 3. التنظيم في تقديم ومتابعة الخدمات الإرشادية \\
\hline & 1 & 0.927 & 0.933 & 0.873 & 4. المسئولية الإجتماعية للجهاز الإرشادي \\
\hline 1 & 0.978 & 0.965 & 0.967 & 0.906 & المقياس الكلي \\
\hline 190.86 & 49.22 & 44.98 & 57.44 & 39.22 & المتوسط الحسابي \\
\hline 21.83 & 5.49 & 5.21 & 6.69 & 5.49 & الانحراف المعياري \\
\hline
\end{tabular}

6.أبعاد و عبارات المقياس في شكلها النهائي

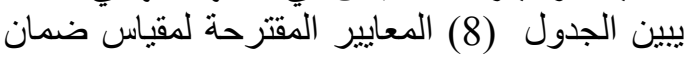

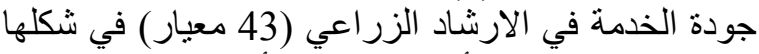
النهائي وموز الخة في على أبعاد المقياس الأربعة.

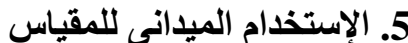

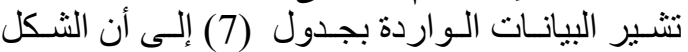

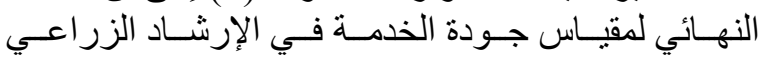

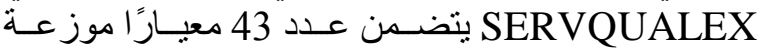
على 4 مكونات فرعية لضمان جودة الخدمة في الارشـاد

جدول (7): بيانات أساسية لمقياس SERVQUALEX في صورته النهائية.

\begin{tabular}{|c|c|c|c|c|c|c|c|}
\hline \multicolumn{3}{|c|}{ 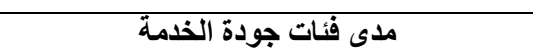 } & \multicolumn{2}{|c|}{ المدى النظري } & \multicolumn{2}{|c|}{ التصورة النهائية } & \multirow[b]{2}{*}{ 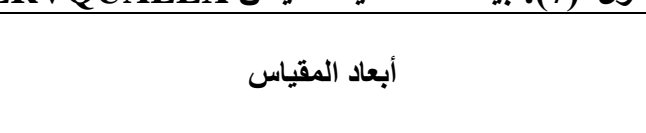 } \\
\hline جودة مرتفعة & جودة متوسطة & منخفضة & الأفصى الحد & الأدنى & $\%$ & المعايير & \\
\hline $45-34$ & $33-22$ & $21-9$ & 45 & 9 & 20.93 & 9 & 1. شكل ومضمون الخدمة الإرشادية \\
\hline $65-48$ & $47-31$ & $30-13$ & 65 & 13 & 30.23 & 13 & 2. العنصر البشري (المرشد) في تقليم الخذمات الإرشادية \\
\hline $50-37$ & $36-24$ & $23-10$ & 50 & 10 & 23.26 & 10 & 3. التنظيم في تقايم ومتابعة الذدمات الإرشادية \\
\hline $55-41$ & $40-26$ & $25-11$ & 55 & 11 & 25.58 & 11 & 4. المسئولية الإجتماعية للجهاز الإرشادي \\
\hline $215-158$ & $157-101$ & $100-43$ & 215 & 43 & 100 & 43 & المقياس الكلي \\
\hline
\end{tabular}

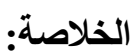
أظهرت نتائج الدر اسة إجتيار مقياس "معايير ضمان

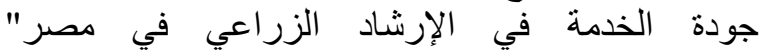
(SERVQUALEX) و الصدق، هذا بالإضافة إلى حصول أبعادة وعبار اته على على الئى

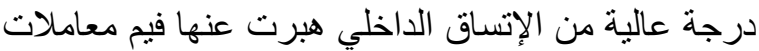

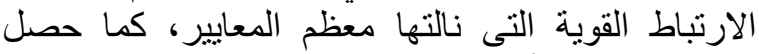

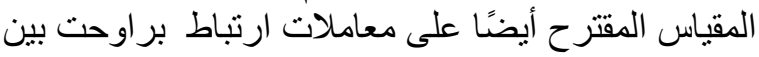
متوسط إلى قوي بين مكونات المقياس الرئيسية وإلى إنمالي

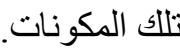

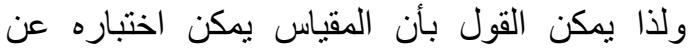

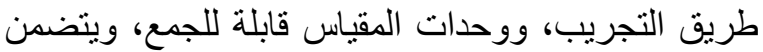

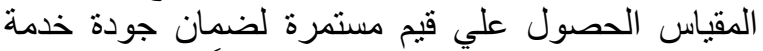

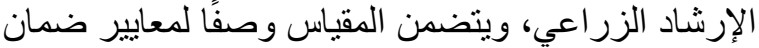

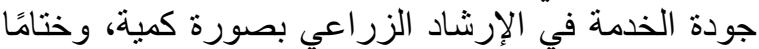

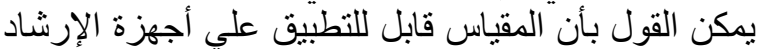
الزر اعي في مصر و الدول المشابهة المابطة.

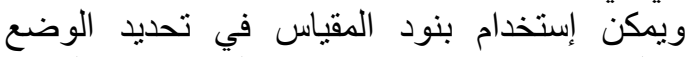

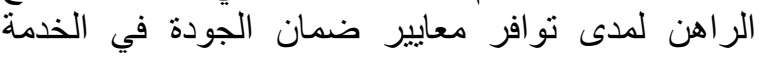

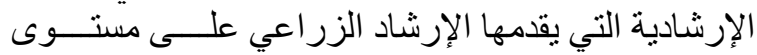

الزر اعي ، بتضمن البعد الأول " شكل ومضمون الخدمـة

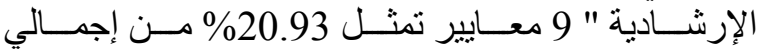
معايير المقياس، وقد بلغ عدد معايير البعد الثناني " العنصر الإنير

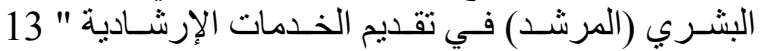

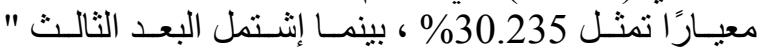

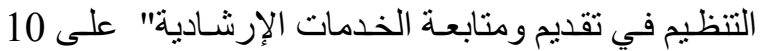

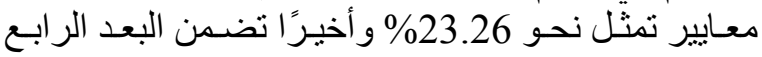

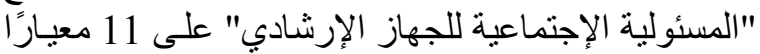

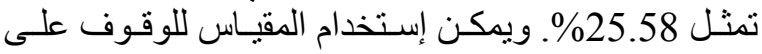

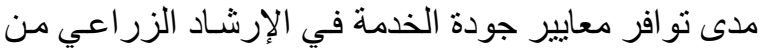

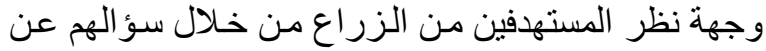

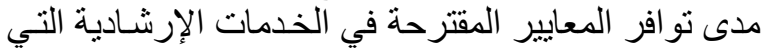

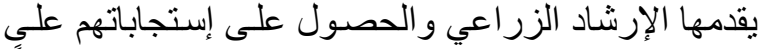

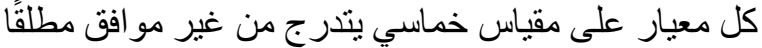

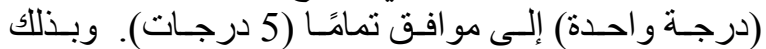

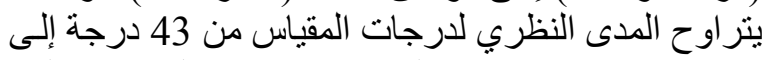

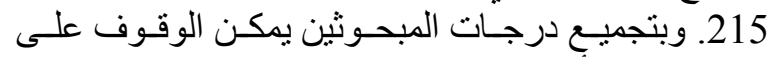

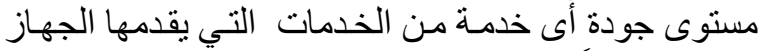

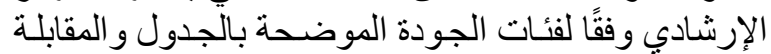
لكل بعد من أبعاد المقياس. 
جدول (8) مقياس معايير ضمان جودة الخدمة في الإرشاد الزراعي SERVQUALEX (الأبعاد والعبارات في صورتها النهائية).

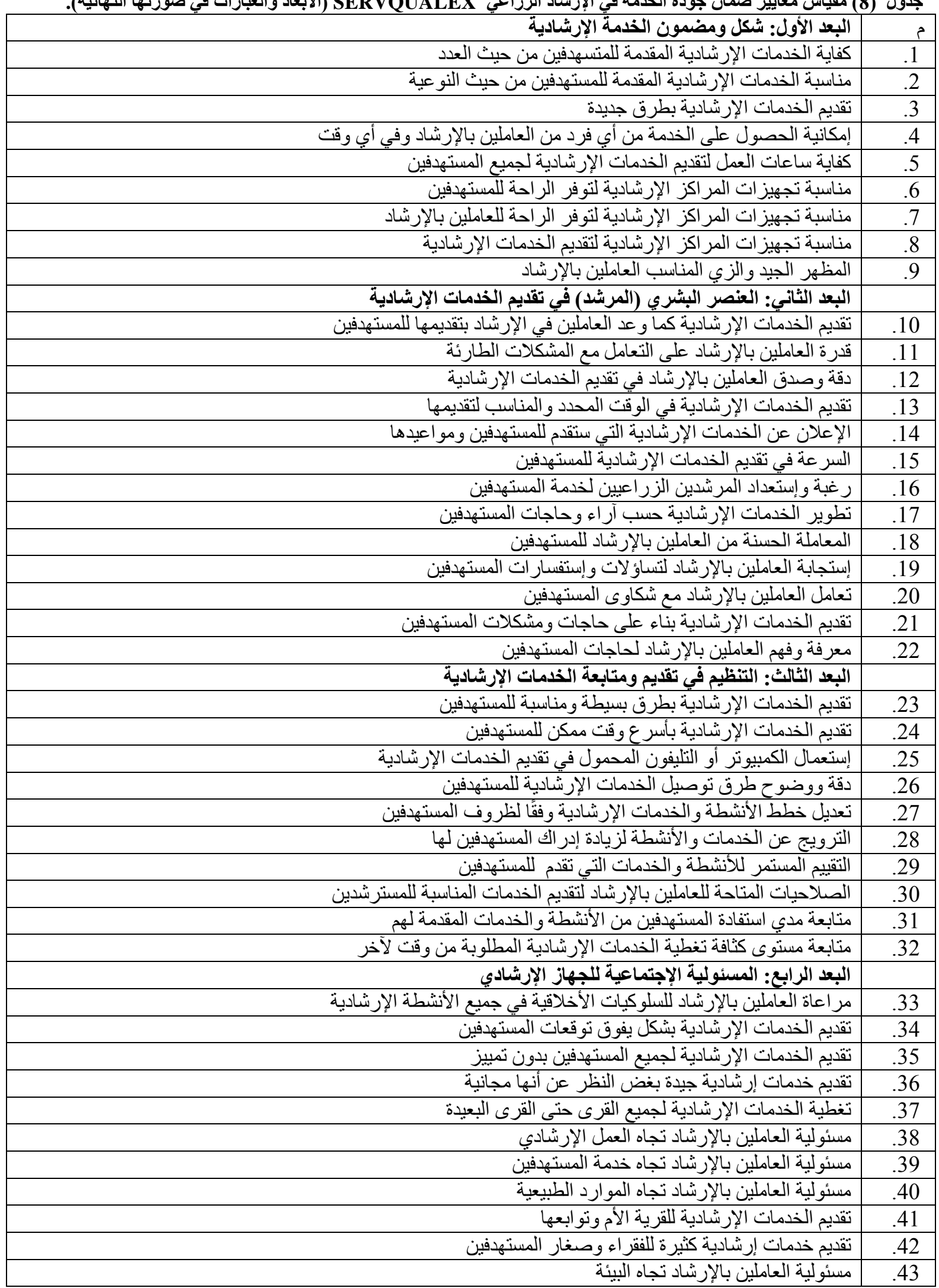

للتأكيد على الجيد منها وتحسين ما هو غير ذلك، وذلك في الإنشي سبيل تحقيق مستوى مقبول من جودة الخدمة الإرشادية فئي الزراعية.
القرية من وجهة نظر الزراع المستهدفين حتى بمكن الوقوف على مستوى جودة الخدمة التئي يقدمها الجهاز

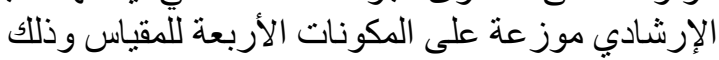




\section{REFERENCES}

Abdel-Ghany M. M. and Diab A. M. (2015). Measuring Agricultural Extension Service Quality in Nubaria Region Using Total Quality and Service Quality Scales. J. Agric. Econ. Soc.l Sci., 6(11): 1737-1750.

Abdel-Ghany M. M. and Diab A. M. (2013). Reforming agricultural extension in Egypt from the viewpoint of central level extension employees. Arab Univ. J. Agric. Sci., 21(2): 143-154.

Abdel-Ghany M.M. M. and Abdel-Salam M. F. S. (2012). Measuring service quality of agricultural extension centers in assiut governorate using SERVPERF scale. J. Agric. Econom. and Social Sci., Mansoura Univ. 3(11): 1569 - 1579.

Alex O. T., Kingori P., Ondiek A.B. (2014). Applicability of SERVQUAL/RATER Model in Assessment of Service Quality Among Local Authorities in Kenya: A Survey of Residents of Nakuru Town. Int 1 J. Econ., Comm. Manag., II (12): 1-16 Available ate: http://ijecm.co.uk/wpcontent/uploads/2014/12/21238.pdf

Boltan R. N. and Drew J.H. (1991). A longitudinal analysis if impact of service changes on customer attitude. J. Mark., 55 (Jan.):1-19

Boulding W., Ajay K., Staelin R. and Valarie A. Zeithaml (1993). A dynamic process model of service quality: from expectations to behavioral intentions. J. Market. Res., 30 (Feb.): 7-27

Buzzell R. D. and Gale B. T. (1987). The PIMS Principles. New York, USA. Free Press.

Connolly R. (2007). Trust and the Taxman: A Study of the Irish Revenue's Website Service Quality. The Electronic Journal of e-Government, 5(2): 27-134. Available at:

Crosby Phillip B. (1979). Quality is Free: The Art of Making Quality Certain, American Liberary New York, USA.

Daniel C. and Berinyuy L. (2010). Using the SERVQUAL model to assess service quality and customer satisfaction. Masters Thesis, Umea University, Sweden. Available at: http://umu.divaportal.org/smash/get/diva2:327600/FULLT EXT01.pdf

El Saghier Niveen and Nathan Demyana (2013). Service Quality Dimensions and

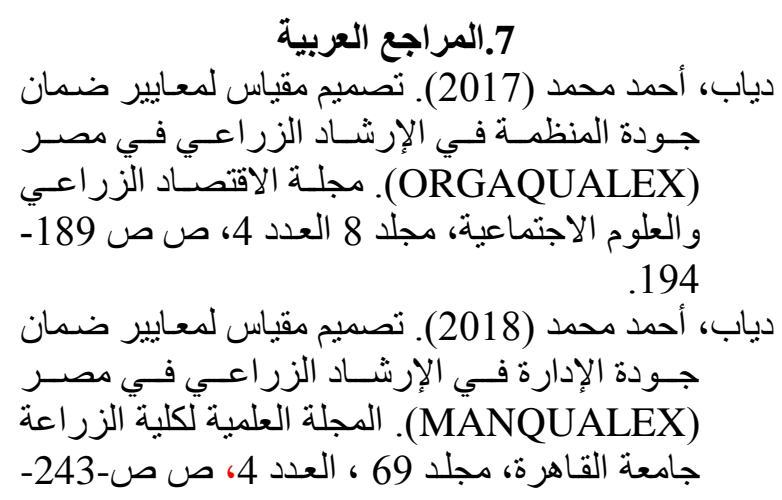

.253 
Customers' Satisfactions of Banks in Egypt. Proceedings of $20^{\text {th }}$ International Business Research Conference 4 - 5 April, Dubai, UAE: 1-13. Available at:

http://www.wbiworldconpro.com/uploads/d ubai-conference-2013april/banking/1364462871_607-Niveen.pdf

Gaster L. (1995). "Quality in Public Services", Open University Press, Buckingham, England.

Gronroos C. (1982). Strategic Management and Marketing in Service Sector, Marketing Science Institute, Cambridge, MA., USA.

Gronroos C. (1990). Service Management and Marketing, Lexington Books, Lexington, MA., USA.

Munhurrun P., Naidoo P. and Bhiwajee S. (2010). Measuring service quality: Perceptions of employees, Global J. Bus. Res., 4 (1): 47-58. Available at: http://www.theibfr2.com/RePEc/ibf/gjbres/ gjbr-v4n1-2010/GJBR-V4N1-2010-4.pdf

Naik C., Gantasala S. and Prabhakar G. (2010). Service quality (Servqual) and its effect on customer satisfaction in retailing, Europ. J. Soc.Sci.,16(2): 231-243. Available at: http://www.eurojournals.com/ejss_16_2_08 .pdf

Parasuraman A., Zeithaml V. and Berry L. (1988). Servqual: a multiple-item scale for measuring customer perceptions of service quality, J. Retail., 64 (1),12-37. Available at:

http://areas.kenanflagler.unc.edu/marketing/ facultystaff/zeithaml/selected\%20publicatio ns/servqual\%20a\%20multipleitem\%20scale
$\% 20$ for $\% 20$ measuring $\% 20$ consumer $\% 20 \mathrm{pe}$ rceptions $\% 20$ of $\% 20$ service $\% 20$ quality.pdf

Reichheld F. F. and Sasser W. E. Jr. (1990). Zero defections: quality comes to service. Harvard Bus. Rev., (Sep-Oct): 77-105.

Ruhana F. (2010). Service quality measurement of Agricultural extension in kosdmps-kp regency of Garut. Int 1 . J. of Kybernology, 1(2): Available at:

https://docs.google.com/viewer?a=v\&pid=sit es\&srcid=axbkbi5hyy5pzhxpam9rlwxwbxxn edo3mzriztllowrmmtc5ywm2

Rust R. T. and Zahorik A. J. (1993). Customer satisfaction, costomer retention and market share. J. Retail., 69(2): 193-215

Sachdev S. B. and Verma H.V. (2004). Relative Importance of Service Quality Diminsions: A Multisectoral Study. J. Serv. Res., 4(1).

Shahin A. and M. Samea (2010). Developing the Models of Service Quality Gaps: A Critical Discussion. Bus. Manag. Strat., (1) 1: 1-11. Available at: http://macrothink.org/journal/index.php/bm s/article/viewFile/395/342

Sureschandar G., Rajendran C. and Kamalanabhan, T. (2001). Customer perceptions of service quality: a critique, Total Quality Management, 12 (1): 111124.

Zahorik A. J. and Rust R. T. (1992). Modelling the impact of service quality on profitability: A review In:"Swartz, T. A., D. E. Bown and S.W. Brown (eds). Advances on services marketing and management. Greenwich, JAI press, CT, San Francisco, California, USA, pp. 49-64. 